\title{
Prediction of the size of annuloplasty ring for mitral valve repair using by three-dimensional transesophageal echocardiography
}

Tasuku Fujit, Kenji Yoshitani, Yoshihiko Ohnishi

Department of Anesthesiology, National Cerebral and Cardiovascular Center, Osaka, Japan

\section{<Background>}

During mitral valve repair for mitral regurgitation (MR)

Cardiovascular Center

The optimal annuloplasty ring $\Rightarrow$ better clinical outcomes.

The size of annuloplasty ring is generally determined by sizer. [cardioplegic arrested heart]

(e.g. 'inter-commissural distance or inter-trigonal distance, and anterior leaflet area)

The transesophageal echocardiography (TEE) can measure the mitral annulus. [beating heart]

\section{Can TEE determine the optimal annuloplasty ring size??}

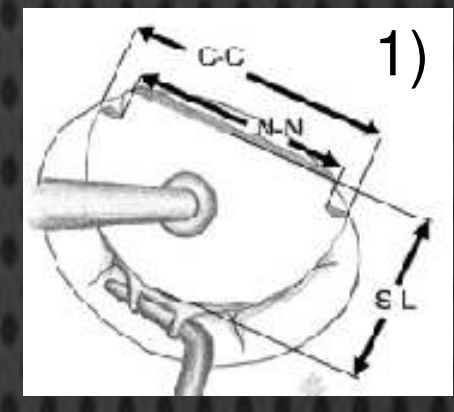

Compared the measurement of mitral valve between sizer and three dimensional (3D) - TEE.

Assessed whether the annuloplasty ring size can be predicted by the $3 \mathrm{D}-\mathrm{TEE}$.

\section{$<$ Methods >}

- Retrospectively, consecutive 133 cases underwent mitral valve repair for degenerative MR between January 2015 and December 2016.

- Using an iE33 ultrasound system and an X7-2t matrix-array transducer (Philips)

$\rightarrow$ The $3 \mathrm{D}$ of mitral valve was collected.

The commissure-commissure (CC) diameter The anterior-posterior (AP) diameter

( the middle anterior leaflet (A2))

- The actual annuloplasty "ring "size "was determined using by sizer.

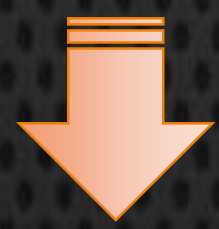

Correlation between the actual annuloplasty ring size by sizer and predicted ring size by $3 D$ TEE. (with multiple regression analysis)

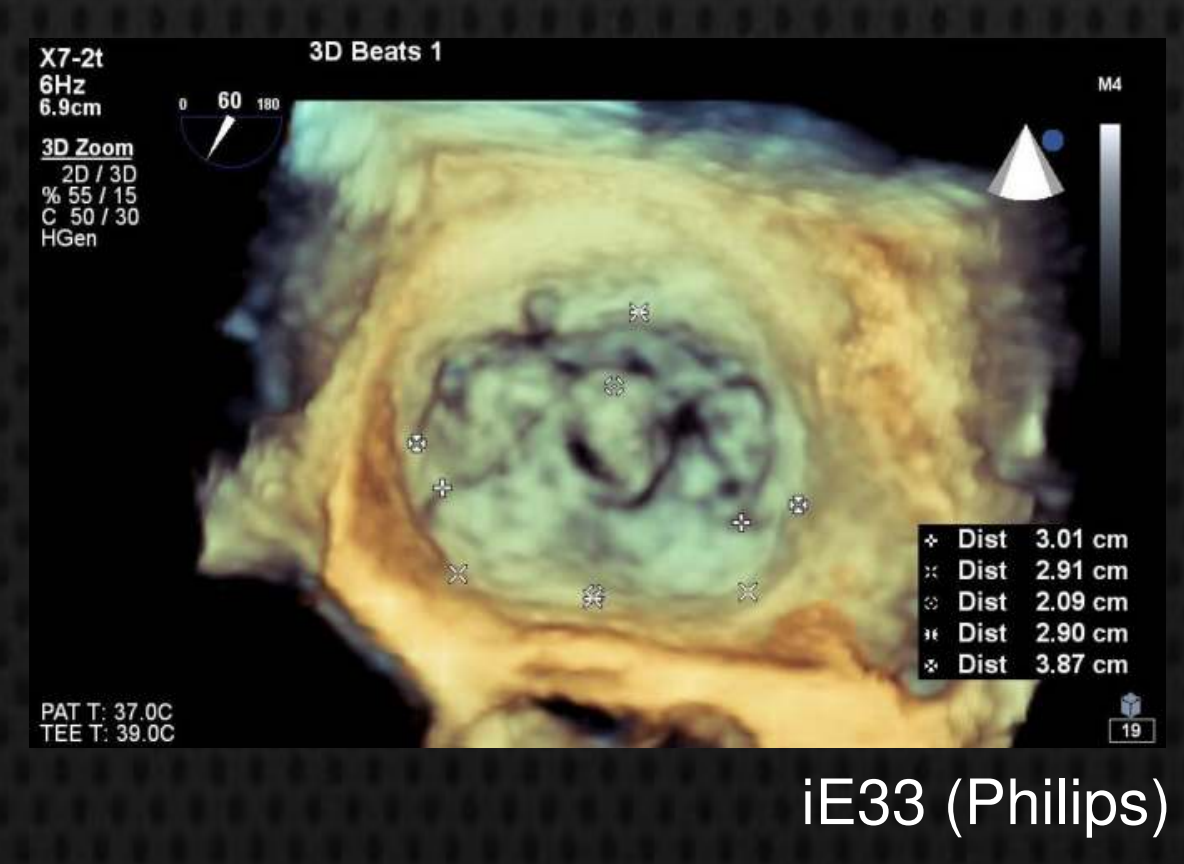

\section{$<$ Conclusion>}

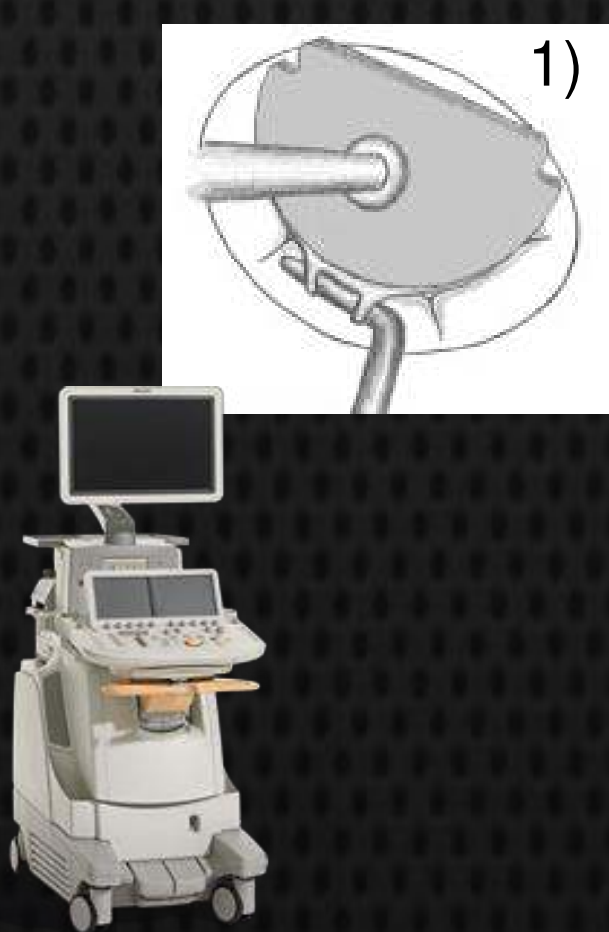

$<$ Results>

The CC diameter: $30.6 \pm 2.2 \mathrm{~cm}$

OThe AP (A2) diameter : $20.6 \pm 2.2 \mathrm{~cm}$

The size of annuloplasty ring : $30.2 \pm 2.1 \mathrm{~cm}$

The multiple regression analysis Annuloplasty ring (cm)

$$
\begin{aligned}
& =4.77+0.77 \times(C C \text { diameter }(\mathrm{cm})) \\
& \therefore 0.09 \times(A P(A 2) \text { diameter }(\mathrm{cm}))
\end{aligned}
$$

The coefficient of determination $\left(\mathbf{R}^{2}\right)$

$$
: 0.76(p<0.001)
$$

The standardized partial regression coefficient The CC diameter : $0.82(\mathrm{p}<0.001)$

The AP (A2) diameter : $0.10(\mathrm{p}=0.044)$

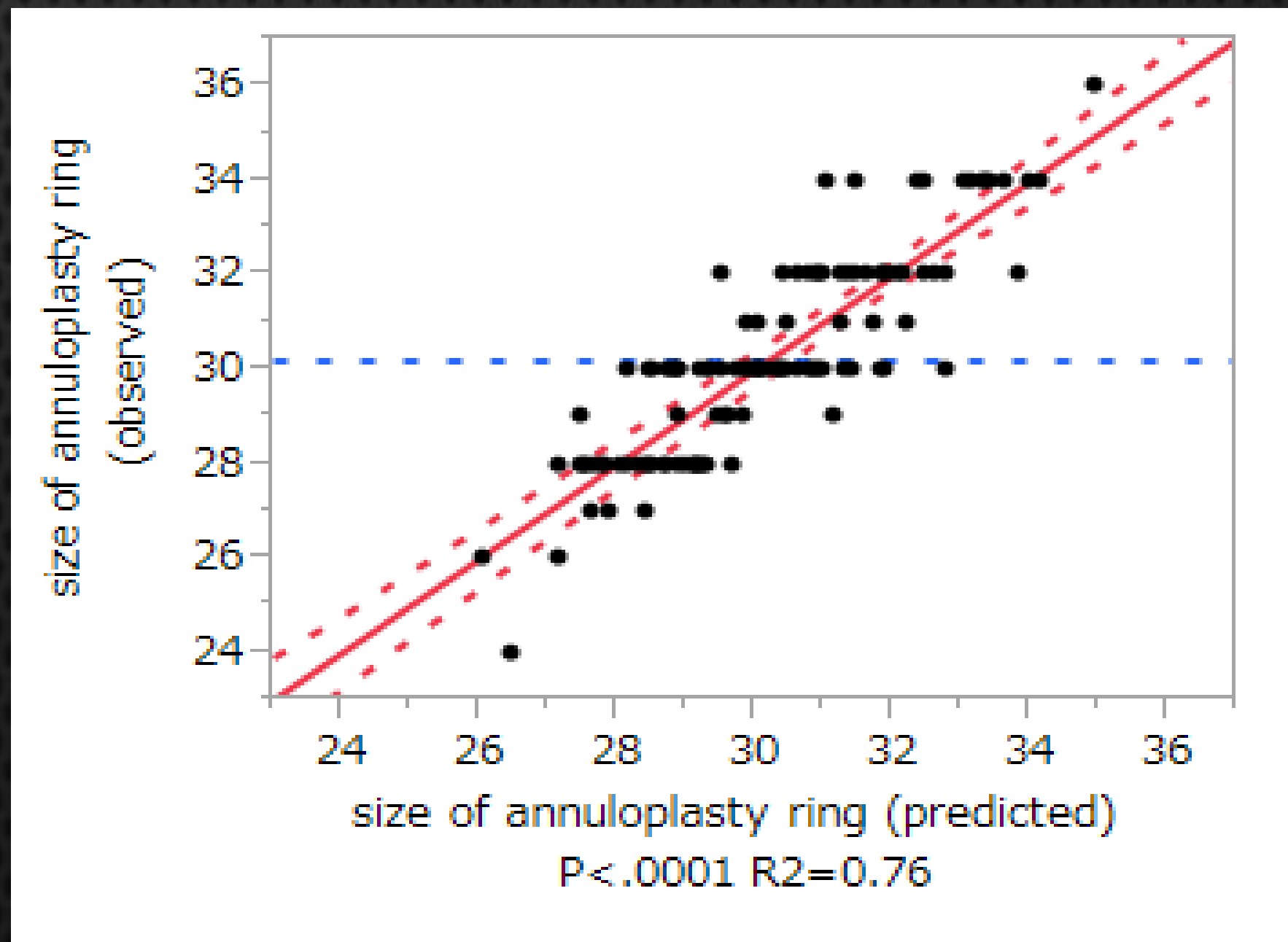

$<$ Ring type >

Cosgrove (50), Physio II (60), Tailor(17), CG Future(6)

There was a strong correlation between sizer and 3D - TEE for measuring the mitral annulus. In particular, $\mathrm{CC}$ diameter of mitral valve is effective for determining the size of annuloplasty ring. 